\title{
Associations between Feeding Patterns and Infant Health in China: A Propensity Score Matching Approach
}

\author{
Yuehui Fang, Yiyao Lian, Zhenyu Yang, Yifan Duan (D) and Yuna He* \\ Key Laboratory of Trace Element Nutrition of National Health and Family Planning Commission, National \\ Institute for Nutrition and Health, Chinese Center for Disease Control and Prevention, No. 29 Nanwei Road, \\ Xicheng District, Beijing 100050, China; fangyh@ninh.chinacdc.cn (Y.F.); lianyy@ninh.chinacdc.cn (Y.L.); \\ yangzy@ninh.chinacdc.cn (Z.Y.); duanyf@ninh.chinacdc.cn (Y.D.) \\ * Correspondence: heyn@ninh.chinacdc.cn; Tel.: +86-10-6623-7233
}

Citation: Fang, Y.; Lian, Y.; Yang, Z.; Duan, Y.; He, Y. Associations between Feeding Patterns and Infant Health in China: A Propensity Score Matching Approach. Nutrients 2021, 13, 4518. https://doi.org/10.3390/nu13124518

Academic Editor: Megumi Haruna

Received: 5 November 2021

Accepted: 15 December 2021

Published: 17 December 2021

Publisher's Note: MDPI stays neutral with regard to jurisdictional claims in published maps and institutional affiliations.

Copyright: (c) 2021 by the authors. Licensee MDPI, Basel, Switzerland. This article is an open access article distributed under the terms and conditions of the Creative Commons Attribution (CC BY) license (https:// creativecommons.org/licenses/by/ $4.0 /)$.
Abstract: Breastmilk is the optimal food for infants. Feeding pattern is closely related to physical development and health during infancy. Understanding the associations between feeding patterns and health status can inform related policy interventions and advocacy in China. This study aimed to investigate the relationship between infant feeding patterns and health status in China infants. The China National Nutrition and Health Surveillance 2013 was a national-representative cross-sectional study performed particularly for children aged $0-5$ years. A total of 3974 infants aged under 1 year were included in the analysis, of whom 1082 (27.2\%) made up the formula feeding group, and 2892 $(72.8 \%)$ made up the breastfeeding group. The associations between feeding patterns and physical development and health were investigated using propensity score matching and multivariable logistic regression models. Among breastfeeding and formula feeding infants aged 9-11 months old, weight-for-age $\mathrm{z}$ score was $1.1 \pm 1.1$ and $0.9 \pm 1.3$, respectively, and weight-for-length $\mathrm{z}$ score was $1.0 \pm 1.3$ and $0.7 \pm 1.4$, respectively. Hemoglobin in $0-2,3-5,6-8$, and 9-11 months old breastfeeding infants was $121.4 \pm 15.2 \mathrm{~g} / \mathrm{L}, 117.1 \pm 13.0 \mathrm{~g} / \mathrm{L}, 113.9 \pm 11.9 \mathrm{~g} / \mathrm{L}$, and $114.4 \pm 14.0 \mathrm{~g} / \mathrm{L}$, while in 0-2, 3-5, 6-8, and 9-11 months formula feeding infants was $116.3 \pm 14.8 \mathrm{~g} / \mathrm{L}, 120.4 \pm 11.3 \mathrm{~g} / \mathrm{L}$, $119.8 \pm 11.2 \mathrm{~g} / \mathrm{L}$, and $120.0 \pm 11.5 \mathrm{~g} / \mathrm{L}$, respectively. Breastfeeding was associated with lower risk of respiratory disease (OR: 0.79; 95\% CI: 0.64, 0.99) and diarrhea (OR: 0.75; 95\% CI: 0.57, 0.98). Breastfeeding could slightly improve infant physical development, and had a protective effect on the diarrheal and respiratory diseases. Infants aged 3-11 months who were breastfeeding showed lower hemoglobin than that of formula-fed infants and thus should increase intake of iron rich complementary foods.

Keywords: infant; feeding pattern; cross-sectional study; propensity score matching

\section{Introduction}

Early nutrition is critical for the development of children. Human milk is the optimal food for infants and is closely related to health during infancy. Early and prolonged breastfeeding has been proven to ensure the best possible health and developmental outcomes for the infant [1]. Exclusive breastfeeding for four to six months is generally considered one of the best protective measures to prevent allergy and associated illnesses [2]. According to previous studies, breastfeeding is protective against acute respiratory infection and diarrhea [3-5], and is considered to be one path to lower healthcare economic costs due to lower incidence of diseases in both breastfed infants and breastfeeding mothers [6]. Breast milk is rich in antimicrobial substances that are important in preventing early-life infections, including immunoglobulins, complement proteins, lysozyme, lactoferrins, and oligosaccharides $[7,8]$. Moreover, human milk consumption introduces the infant to highly diverse and complex bacterial communities [9]. The World Health Organization (WHO) and Chinese dietary guidelines both recommend that children be exclusively breastfed for six months, and continue to be breastfed until two years of age or beyond [10]. 
The majority of people's lifestyles have changed dramatically in both rural and urban areas as a result of China's process of urbanization. The feeding patterns of infants under the age of 12 months have changed greatly. Since the 1990s, China has made numerous efforts to encourage breastfeeding [11]. However, between 1985 and 2015, in China's urban area, the formula feeding rate among infants under 6 months and the continuous breastfeeding rate at 1 year of age were remained stable at around $15 \%$ and $30 \%$, respectively, while in the suburbs, the formula feeding rates increased from $6.5 \%$ to $15.2 \%$ and continuous breastfeeding rates decreased from $60.1 \%$ to $29.8 \%$ [12]. According to the most recent results of the Chinese nutrition and health survey in 2013, exclusive breastfeeding rate among infants aged 0-6 months was 18.6\% [13].

Feeding pattern is one of the environmental determinants related to weight gain and subsequent obesity [14]. Breastfeeding has been regarded as associated with lower weight and length gain throughout infancy when compared with formula feeding [15]. Formula-fed infants, on the other hand, are believed to be more prone to acquire weight and develop out of proportion to linear growth [16]. Breastfeeding is also thought to play a role in preventing obesity in infants and non-communicable diseases in adults [17]. Nevertheless, some studies yielded contradictory results. A recent study reported that the amount of formula was unrelated to weight [18]. A systematic review showed that an inverse association between exclusive breastfeeding duration and weight and length gain during infancy was only found in the developed setting [19]. Another systematic review suggested that breastfeeding may protect against being overweight or obese, but residual confounding cannot be ruled out [20].

As far as we know, except for feeding practice, biomedical and behavioral factors could also influence physical and immune system development during infancy [21], including preterm delivery [22], low birth weight (LBW) and intrauterine growth restriction [23], infectious diseases [24], sleep duration [25,26], physical activities [27], and complementary food feeding $[28,29]$. Infant development may be influenced by sociodemographic and maternal factors such as maternal gestational weight gain [30], gestational age, employment and education, family income and regional economic level [24-31] could also affect infant development. These variables were also related to infants' feeding patterns [32]. These confounding factors may have an impact on the results of infant feeding studies.

In light of the above, it is critical to account for confounding factors when assessing the relationship between feeding patterns and physical and heath health in infants, which necessitates the use of proper study methods. Knowing the association between feeding patterns and physical health in Chinese infants is essential to health practitioners and policymakers in China and will help to promote infant health.

\section{Materials and Methods}

\subsection{Data Sources}

Data for this study was obtained from the 2013 China National Nutrition and Health Survey (CNNHS). The China National Nutrition and Health Surveillance 2010-2013 was a national-representative cross-sectional study that covered 30 provinces. It was conducted by the National Institute of Nutrition and Health, Chinese Center for Disease Control and Prevention (NINH, Chinese Center for Disease Control and Prevention). All of the participants in this study were selected during the surveillance round 2013, which targeted children aged 0 to 5 and lactating mothers. The surveillance used stratified proportional random cluster sampling methods to ensure it had national representatives. As described in previous study, a total of 2865 districts/counties in China were categorized into four strata (large cities, medium and small cities, general rural areas, and poor rural areas), from which 55 counties (12 metropolis, 15 medium and small cities, 18 general rural areas, and 10 poor rural areas) were chosen in the study. In each selected county, three communities/townships were systematically sampled. In each selected township, three neighborhood/villages were systematically selected. Finally, 10 children from each age group were randomly selected in each selected village [13]. All participants and their 
guardians were required to complete an informed consent form before participating in the study. The Ethics Review Board of the Institute for Nutrition and Health, China CDC approved the protocol (2013-018). Only infants and their mothers both with complete basic and diet information were included in the analysis. Separate analyses were carried out for infants aged 0-2 months, 3-5 months, 6-8 months, and 9-11 months (Figure 1).

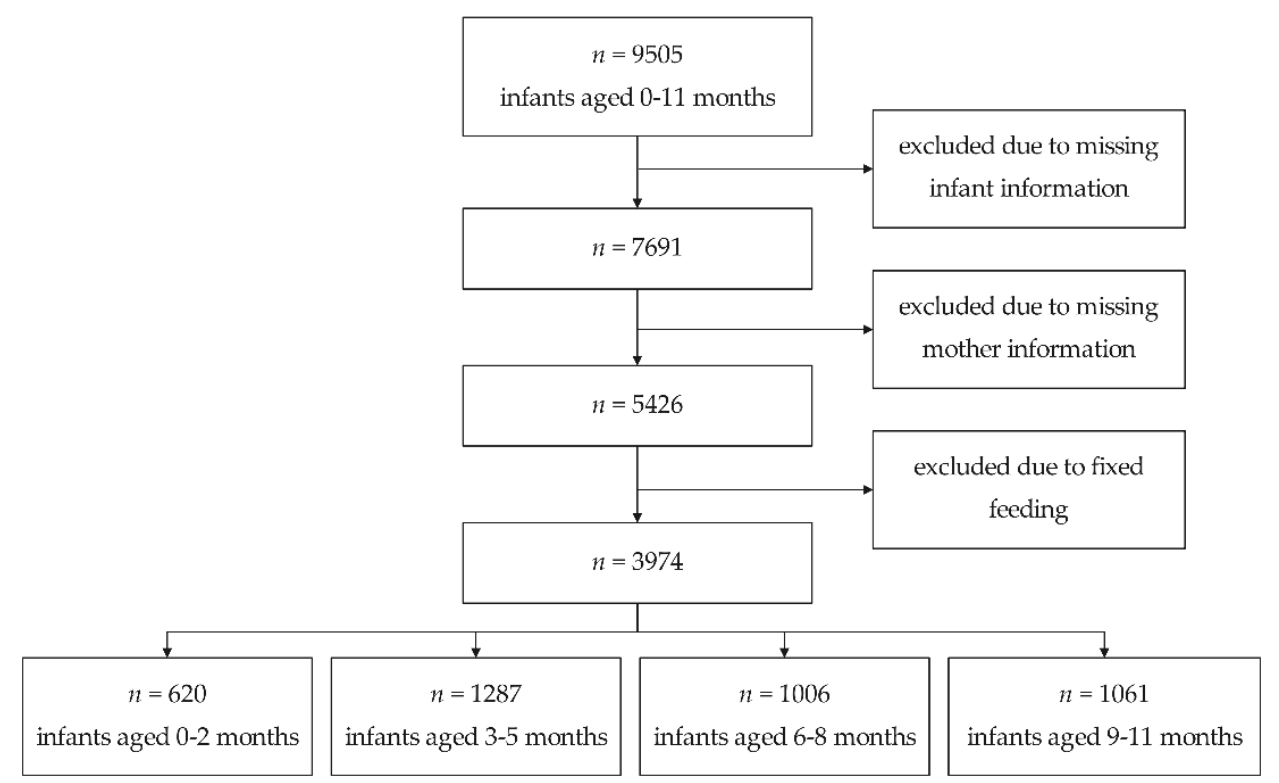

Figure 1. Flowchart of study participants selection.

\subsection{Outcome Variables}

The outcome variables were body length, body weight, weight-for-age $z$ score, lengthfor-age z score, weight-for-length z score, hemoglobin, and prevalence of respiratory disease and diarrheal disease. Z-scores were calculated based on the WHO Child Growth Standards based on length/height, weight, and age [33]. Respiratory disease and diarrheal disease were measured based on maternal recall of symptoms of cough and shortness of breath, and diarrhea during the last two weeks, respectively. Blood samples were collected from infants' finger using capillary blood extraction. Cyanide high-iron method was used to determine hemoglobin concentration.

\subsection{Exposure Variables}

We investigated infants' intake of breast milk, formula, and complementary food during the previous week. Breastfeeding data were collected by recall interviews carried out face-to-face with the parents or caregivers of the infants. Feeding patterns were classified into two types for infants under 1 year of age based on their sources of milk.

- Breastfeeding infants were those whose source of milk was only breast milk (inclusive of mother's own milk by bottle);

- Formula feeding were those whose source of milk was only formula.

Because the proportion of feedings containing breast milk is unknown, fixed feeding was not included in the analysis.

\subsection{Potential Confounders}

The potential confounders were selected based on the results of previously published studies [21-31] and the availability of data. Potential confounding factors were broadly classified into socioeconomic and demographic factors, biomedical and behavioral factors, and maternal factors.

Socioeconomic and demographic factors included place of usual residence, household wealth status, and mother's education and occupation. Based on the socio-economic level 
of the survey sites, places of usual residence were classified as big cities, medium and small cities, normal rural, and poor rural. Annual household income per capita was classified into three categories: low (CNY 10,000), medium (CNY 10,000-19,999), and high (CNY $20,000)$ to describe household wealth status. Mother's education was categorized into four categories: elementary school or below, junior school, high school, high school, and college and above. Mother's occupation was categorized into three categories: professionals, working in the agricultural industry, and others.

Infant biomedical and behavioral factors included gestational age, birth weight, physical activity, sleep duration, and complementary food intake. Gestational age was divided into two groups: preterm infants were defined as gestational age $<37$ weeks, term infants were defined as gestational age $\geq 37$ weeks. Birth weight was divided into three groups. Low birth weight (LBW) was defined as birth weight $<2500 \mathrm{~g}$, whereas macrosomia was defined as birth weight $>4000 \mathrm{~g}$. According to Guidelines on physical activity, sedentary behavior, and sleep for children under 5 years of age [34], the continuous variable reflecting hours of sleep duration was dichotomized into sufficient (sleep duration $\geq 14 \mathrm{~h}$ /day for infant younger than 3 months, sleep duration $\geq 12 \mathrm{~h}$ /day for infant above 3 months) and insufficient (sleep duration $<14 \mathrm{~h}$ /day for infant younger than 3 months, sleep time $<12 \mathrm{~h}$ /day for infant above 3 months), and physical activity time was dichotomized into high (activity time $\geq 30 \mathrm{~min} /$ day) and low (activity time $<30 \mathrm{~min} /$ day). For infants over the age of 6 months, complementary food was matched to the types of complementary foods consumed in the previous week, which included grains, tubers, vegetables, fruits, legumes, eggs, meat, aquatic products, and dairy.

Maternal factors included maternal age and gestational weight gain. Maternal age was categorized into three categories: $<20$ years, 25-35 years, and >35 years. Gestational weight gain was categorized into insufficient, appropriate, and excessive according to the Institute of Medicine (IOM) [35].

\subsection{Statistical Analysis}

Data were entered through a standardized data management platform and were cleaned for all variables. Normally distributed data were assessed using the paired $t$-test, whereas for non-normally distributed data, a paired Wilcoxon rank-sum test was applied. A chi-square test was used for categorical variable comparison.

Propensity score matching (PSM) analysis was performed to reduce potential selection bias with the potential confounders. Even though cross-sectional surveys are useful for examining the relationships between exposure and outcome variables, unlike randomized controlled trials (RCTs), non-randomized self-selection in the exposure could confound the measure of association between the exposures and the outcomes [36]. Rosenbum and Rubin [37] proposed the PSM method to minimize the imbalance in participant characteristics between exposed and unexposed groups by considering the confounding between the two groups. PSM is a method for balancing the propensity scores of the exposed and unexposed groups so that covariate comparisons between the two groups can be made directly.

Multivariable logistic regression was used to investigate the associations between feeding patterns and respiratory and diarrheal diseases. Odds ratios (ORs) with 95\% confidence intervals (CIs) were reported as the measure of association between feeding patterns and diseases. Data clean and analysis were performed using SAS 9.4 software (SAS Institute Inc., Cary, NC, USA). Propensity scoring and matching were conducted using the MatchIt package (version 4.1.0) for $R$ software ( $R$ for Windows 4.0.5).

\section{Results}

The general characteristics before and after matching were described in Table 1. A total of 3974 infants were included in the analysis, of whom $1082(27.2 \%)$ made up the formula feeding group, 2892 (72.8\%) made up the breastfeeding group. Of the total infants, $2226(56.0 \%)$ were from urban areas and $1748(44.0 \%)$ were from rural areas, 2014 were 
boys (50.7\%) and 1960 were girls (49.3\%). Breastfeeding infants made up nearly three times the number of formula-fed infants. Between two feeding groups, there were differences in living area, annual income per capita, whether the infant was born to term or not, birth weight, physical activity time, complementary food intake, and mother's educational level and occupation. After propensity score matching, no significant differences were found between two groups for the matched covariates.

Table 1. Infant, family, and maternal characteristics before and after matching, $\mathrm{N}(\%)$.

\begin{tabular}{|c|c|c|c|c|c|c|}
\hline \multirow{2}{*}{ Covariates } & \multicolumn{3}{|c|}{ Before Matching } & \multicolumn{3}{|c|}{ After Matching } \\
\hline & Breastfeeding & Formula Feeding & $p$-Value & Breastfeeding & Formula Feeding & $p$-Value \\
\hline $\mathrm{N}$ & 2892 & 1082 & & 941 & 941 & \\
\hline Age (day) & $177.4 \pm 90.4$ & $247.6 \pm 88.9$ & $<0.001$ & $235.7 \pm 89.8$ & $236.5 \pm 89.0$ & 0.888 \\
\hline Age group & & & $<0.001$ & & & 1.000 \\
\hline $0-2$ months & $549(19.0)$ & $71(6.6)$ & & $71(7.6)$ & $71(7.6)$ & \\
\hline 3-5 months & $1081(37.4)$ & $206(19.0)$ & & $204(20.7)$ & $204(20.7)$ & \\
\hline $6-8$ months & $716(24.8)$ & $290(26.8)$ & & $278(29.5)$ & $278(29.5)$ & \\
\hline 9-11 months & $546(18.9)$ & $515(47.6)$ & & $388(41.2)$ & $388(41.2)$ & \\
\hline Sex & & & 0.811 & & & 0.782 \\
\hline Boys & $1469(50.8)$ & $545(50.4)$ & & $472(50.2)$ & $478(50.8)$ & \\
\hline Girls & $1423(49.2)$ & $537(49.6)$ & & $469(49.8)$ & $463(49.2)$ & \\
\hline Area & & & $<0.001$ & & & 0.670 \\
\hline Big city & $673(23.3)$ & $334(30.9)$ & & $288(30.6)$ & $292(31.0)$ & \\
\hline Medium and small city & 807 (27.9) & $412(38.1)$ & & $307(32.6)$ & $327(34.8)$ & \\
\hline Normal rural & $1043(36.1)$ & $245(22.6)$ & & $246(26.1)$ & $231(24.5)$ & \\
\hline Poor rural & $369(12.8)$ & $91(8.4)$ & & $100(10.6)$ & $91(9.7)$ & \\
\hline Annual income per capita & & & $<0.001$ & & & 0.973 \\
\hline Low & $997(34.5)$ & $290(26.8)$ & & $271(28.8)$ & $275(29.2)$ & \\
\hline Medium & $851(29.4)$ & $284(26.2)$ & & $247(26.2)$ & $242(25.7)$ & \\
\hline High & $781(27.0)$ & $384(35.5)$ & & $322(34.2)$ & $318(33.8)$ & \\
\hline Unknown & $263(9.1)$ & $124(11.5)$ & & $101(10.7)$ & $106(11.3)$ & \\
\hline Born to term & & & 0.002 & & & 1.000 \\
\hline Term & $2598(89.8)$ & $935(86.4)$ & & $823(87.5)$ & $823(87.5)$ & \\
\hline Preterm & 294(10.2) & $147(13.6)$ & & $118(12.5)$ & $118(12.5)$ & \\
\hline Birth weight & & & $<0.001$ & & & 0.545 \\
\hline$<2500 \mathrm{~g}$ & $50(1.7)$ & $66(6.1)$ & & $35(3.7)$ & $44(4.7)$ & \\
\hline $2500-4000 \mathrm{~g}$ & $2682(92.7)$ & $970(89.6)$ & & $865(91.9)$ & $853(90.6)$ & \\
\hline$>4000 \mathrm{~g}$ & $160(5.5)$ & $46(4.3)$ & & $41(4.4)$ & $44(4.7)$ & \\
\hline Sleep duration & & & 0.013 & & & 0.886 \\
\hline Sufficient & $1727(59.7)$ & $693(64.0)$ & & $598(63.5)$ & $595(63.2)$ & \\
\hline Insufficient & $1165(40.3)$ & $389(36.0)$ & & $343(36.5)$ & $346(36.8)$ & \\
\hline Physical activity time & & & $<0.001$ & & & 0.806 \\
\hline High & $1390(48.1)$ & $761(70.3)$ & & $633(67.3)$ & $628(66.7)$ & \\
\hline Low & 1502 (51.9) & $321(29.7)$ & & $308(32.7)$ & $313(33.3)$ & \\
\hline Types of complementary & & & & & & \\
\hline food & $4.2 \pm 2.2$ & $3.0 \pm 2.4$ & $<0.001$ & $3.8 \pm 2.4$ & $4.0 \pm 2.2$ & 0.201 \\
\hline Maternal age & & & 0.057 & & & 0.979 \\
\hline$<20$ years old & $118(4.1)$ & $32(3)$ & & $30(3.2)$ & $29(3.1)$ & \\
\hline 20-35 years old & $2572(88.9)$ & $956(88.4)$ & & $831(88.3)$ & $830(88.2)$ & \\
\hline$>35$ years old & $202(7.0)$ & $94(8.7)$ & & $80(8.5)$ & $82(8.7)$ & \\
\hline Gestational weight gain & & & 0.560 & & & 0.872 \\
\hline Insufficient & $784(27.1)$ & $278(25.7)$ & & $231(24.5)$ & $236(25.1)$ & \\
\hline Appropriate & $1051(36.3)$ & $391(36.1)$ & & $345(36.7)$ & $351(37.3)$ & \\
\hline Excessive & $1057(36.5)$ & $413(38.2)$ & & $365(38.8)$ & $354(37.6)$ & \\
\hline Mother's education & & & $<0.001$ & & & 0.995 \\
\hline Elementary school or & & & & & & \\
\hline below & $258(8.9)$ & $74(6.8)$ & & $68(7.2)$ & $69(7.3)$ & \\
\hline Junior school & $1396(48.3)$ & $391(36.1)$ & & $362(38.5)$ & $361(38.4)$ & \\
\hline High school & $579(20.0)$ & $266(24.6)$ & & $222(23.6)$ & $218(23.2)$ & \\
\hline College and above & $659(22.8)$ & $351(32.4)$ & & $289(30.7)$ & $293(31.1)$ & \\
\hline Mother's occupation & & & $<0.001$ & & & 0.827 \\
\hline Professionals & $614(21.2)$ & 349 (32.3) & & $259(27.5)$ & $271(28.8)$ & \\
\hline Agricultural industry & $334(11.5)$ & $86(7.9)$ & & $77(8.2)$ & $76(8.1)$ & \\
\hline Others & $1944(67.2)$ & $647(59.8)$ & & $605(64.3)$ & $594(63.1)$ & \\
\hline
\end{tabular}

In all age groups, there was little difference in infant body length between the breastfeeding and formula feeding groups. The difference of body weight between the two 
groups was minimal among infants under 6 months of age. However, among infants aged 6 to 11 months, body weight, weight-for-age $\mathrm{z}$ score and weight-for-length $\mathrm{z}$ score were significantly higher in breastfeeding group than those in formula feeding group. With the exception of the $0-2$ months group, hemoglobin in the breastfeeding group was significantly lower compared with the formula feeding group (Table 2, Figure 2).

Table 2. Infant physical development in breastfeeding and formula feeding group after matching.

\begin{tabular}{|c|c|c|}
\hline & Breast Feeding & Formula Feeding \\
\hline \multicolumn{3}{|l|}{ 0-2 months } \\
\hline weight-for-age z score & $1.3 \pm 1.6$ & $1.5 \pm 2.4$ \\
\hline length-for-age z score & $0.4 \pm 2.1$ & $0.7 \pm 3.1$ \\
\hline weight-for-length z score & $1.1 \pm 1.8$ & $1.0 \pm 1.9$ \\
\hline \multicolumn{3}{|l|}{$3-5$ months } \\
\hline weight-for-age z score & $1.2 \pm 1.1$ & $1.0 \pm 1.6$ \\
\hline length-for-age $\mathrm{z}$ score & $0.7 \pm 1.2$ & $0.6 \pm 1.7$ \\
\hline weight-for-length z score & $0.9 \pm 1.3$ & $0.6 \pm 1.7$ \\
\hline \multicolumn{3}{|l|}{$6-8$ months } \\
\hline weight-for-age z score & $1.3 \pm 1.2$ & $1.1 \pm 1.0$ \\
\hline length-for-age z score & $0.7 \pm 1.6$ & $0.7 \pm 1.7$ \\
\hline weight-for-length z score & $0.9 \pm 1.4$ & $0.6 \pm 1.4$ * \\
\hline \multicolumn{3}{|l|}{ 9-11 months } \\
\hline weight-for-age z score & $1.1 \pm 1.1$ & $0.9 \pm 1.3 *$ \\
\hline length-for-age z score & $0.3 \pm 1.3$ & $0.3 \pm 1.3$ \\
\hline weight-for-length z score & $1.0 \pm 1.3$ & $0.7 \pm 1.4^{* *}$ \\
\hline
\end{tabular}
${ }^{*} p<0.05 ;{ }^{* *} p<0.01$.

The prevalence of respiratory and diarrheal diseases during the last two weeks in breastfeeding group was lower than that in the formula feeding group (Table 3). Breastfeeding was found to have a significant protective effect against respiratory diseases in infants aged 3-5 months. Infants aged 6-8 months showed a significant protective effect against diarrhea. However, the protective effect on diarrhea among 0-2 months old infants was nearly reached statistical significance $(p=0.054)$.

Table 3. Association between breastfeeding and prevalence of respiratory diseases and diarrhea in the last two weeks, $\mathrm{N}(\%)$.

\begin{tabular}{|c|c|c|c|c|c|}
\hline & $\mathbf{N}$ & Respiratory Diseases & OR $(95 \%$ CI $)$ & Diarrhea & OR $(95 \% \mathrm{CI})$ \\
\hline \multicolumn{6}{|l|}{ 0-2 months } \\
\hline Formula feeding & 71 & $8(11.3)$ & ref & $10(14.1)$ & ref \\
\hline Breastfeeding & 71 & $3(4.2)$ & $0.35(0.09,1.37)$ & $3(4.2)$ & $0.27(0.07,1.02)$ \\
\hline \multicolumn{6}{|l|}{$3-5$ months } \\
\hline Formula feeding & 191 & 38 (18.6) & ref & $29(14.2)$ & ref \\
\hline Breastfeeding & 191 & $23(11.3)$ & $0.56(0.32,0.97)$ * & $23(11.3)$ & $0.77(0.43,1.38)$ \\
\hline \multicolumn{6}{|l|}{ 6-8 months } \\
\hline Formula feeding & 278 & $65(23.4)$ & ref & $42(15.1)$ & ref \\
\hline Breastfeeding & 278 & $61(21.9)$ & $0.92(0.62,1.37)$ & $25(9.0)$ & $0.56(0.33,0.94)$ * \\
\hline \multicolumn{6}{|l|}{ 9-11 months } \\
\hline Formula feeding & 388 & $105(27.1)$ & ref & $53(13.7)$ & ref \\
\hline Breastfeeding & 388 & $93(24.3)$ & $0.85(0.61,1.17)$ & $53(13.7)$ & $1.00(0.66,1.51)$ \\
\hline \multicolumn{6}{|l|}{ Total } \\
\hline Formula feeding & 928 & $216(23.3)$ & ref & $134(14.4)$ & ref \\
\hline Breastfeeding & 928 & $180(19.4)$ & $0.79(0.64,0.99)$ * & $104(11.2)$ & $0.75(0.57,0.98)$ * \\
\hline
\end{tabular}




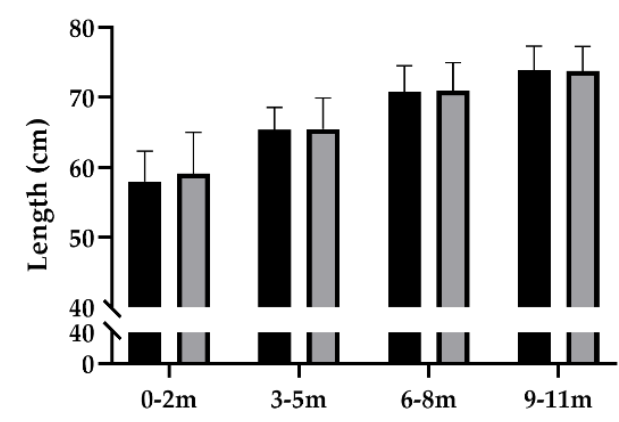

(a)

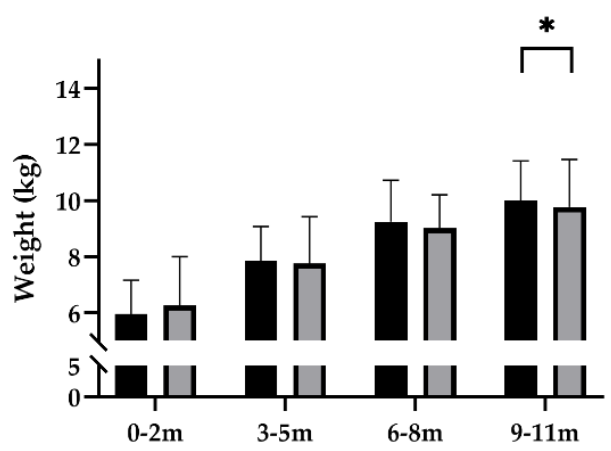

(b)

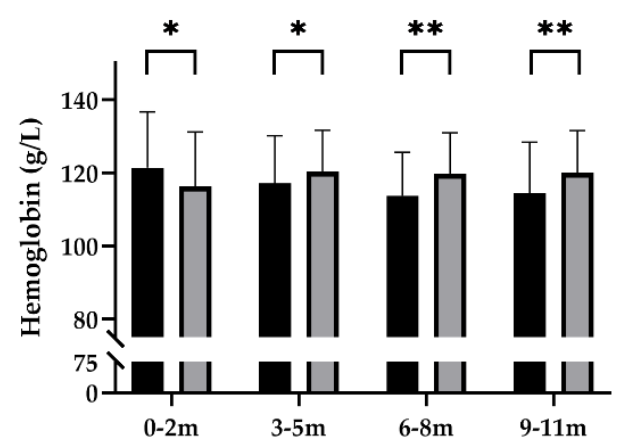

(c)
Breastfeeding
Formula Feeding
Breastfeeding

$\square$ Formula Feeding

Figure 2. (a) Body length in breastfeeding and formula feeding 0-2, 3-5, 6-8 and 9-11 month infants was $58.0 \pm 4.4$ vs. $59.1 \pm 5.9,65.4 \pm 3.2$ vs. $65.5 \pm 4.5,70.8 \pm 3.7$ vs. $71.0 \pm 4.0$, and $73.8 \pm 3.5$ vs. $73.8 \pm 3.5$, respectively; (b) body weight in breastfeeding and formula feeding $0-2,3-5,6-8$ and $9-11$ month infants was $6.0 \pm 1.2$ vs. $6.3 \pm 1.8,7.9 \pm 1.2$ vs. $7.8 \pm 1.7,9.3 \pm 1.5$ vs. $9.0 \pm 1.2$, and $10.0 \pm 1.4$ vs. $9.8 \pm 1.7$, respectively; (c) hemoglobin in breastfeeding and formula feeding $0-2$, 3-5, 6-8 and 9-11month infants was $121.4 \pm 15.2$ vs. $116.3 \pm 14.8,117.1 \pm 13.0$ vs. $120.4 \pm 11.3$, $113.9 \pm 11.9$ vs. $119.8 \pm 11.2$, and $114.4 \pm 14.0$ vs. $120.0 \pm 11.5$, respectively; ${ }^{*} p<0.05 ;{ }^{* *} p<0.01$.

\section{Discussion}

By using the national representative data, we described the status of breast and formula feeding in different sociodemographic population in China. Breastfeeding rates among infants under 1 year of age have been declining as they have grown older. Breastfeeding had a positive effect on weight gain in infants aged 6 months and up, according to our findings. However, no significant association has been observed between feeding pattern and body length gain in infants under the age of one. When compared to formula feeding, breastfeeding was linked to a lower risk of diarrhea and respiratory diseases. Despite these benefits, breastfeeding was associated with a lower hemoglobin level in infants older than 3 months. 
Consistent with previous studies [24-32], we found that sociodemographic, biomedical, behavioral, and maternal factors, such as family income and regional economic status, as well as maternal employment and education, were all strongly related to the infant feeding patterns. During the process of urbanization in China, the maternal employment rate has risen dramatically. Several studies have indicated that the duration of maternity leave has a significant impact on the sustainability of breastfeeding among female workers [38,39]. Our study found that infants under 3 months of age were mostly $(91.70 \%)$ breastfed, while only half of the infants older than 9 months were breastfed. Breastfeeding rates in big cities, medium and small cities, normal rural areas, and poor rural areas were $68.8 \%, 68.2 \%, 82.0 \%$, and $81.0 \%$, respectively. With the increasing annual income per capita, the breastfeeding rate decreased from $78.5 \%$ to $69.4 \%$. These results might be attributed to the employment of mothers. Previous studies had demonstrated that employed mothers were more likely to have lower breastfeeding rate than unemployed mothers [40-43]. In China, the legal maternity leave is 98 days, and can be extended up to seven months by the employers. This might explain the phenomenon of a high breastfeeding rate under 3 months compared to a low breastfeeding rate after 9 months. The childbearing age of mothers could be another factor affecting infant feeding practice. Previous studies have shown that older mothers are more likely to breastfeed, but this study found that the breastfeeding rates decreased as mothers' ages increased. This might be related to the socio-economic status. Mothers with a maternal age of older than 35 years might be more likely to have a better economic status and a higher work participation, making it more difficult to breastfeed. As a result, national policies are critical in reducing the conflict between employment and sustained breastfeeding [39].

Breast milk is optimal and essential for infant growth and development, and provides a rich source of early nutrition for infant growth and development [44]. Consistent with previous study [45], our study suggested that weight and length gain showed no significant statistical difference among formula-fed infants and breastfed infants for infants aged under 6 months. As for infants 6-11 months, we found that breastfeeding had some benefit on weight gain. According to a previous study, even if breastfeeding infants have a higher weight and BMI than bottle feeding infants, breastfeeding was still associated with a reduction in the odds of overweight and obesity [46]. On the other hand, the proportion of energy from complementary foods largely increased among infants aged 9-11 months, which may present addition confounding factors influencing physical development. Nevertheless, these results reflected that breast milk alone cannot provide sufficient nutrients for infant growth and development was a misperception [47]. However, there are still a number of mothers who do not have sufficient breast milk to ensure baby's growth. Moreover, preterm infants and infants with specific diseases need special medical formula to ensure their growth [48]. Therefore, formula is essential for these infants.

Evidence has shown that breastfeeding is associated with reduced infant morbidity and mortality attributable to diarrheal and respiratory diseases. A cohort study had demonstrated that an estimated $53 \%$ of diarrhea hospitalizations could have been prevented per month by exclusive breastfeeding and $31 \%$ by partial breastfeeding in the first 8 months after birth [49]. Another cohort study supports this result that formula feeding for $\geq 3$ months was associated with higher odds of diarrhea between 6 and 12 months [50]. A recent systematic review showed that the pooled relative risk of diarrhea incidence among infants aged $\leq 6$ months was 0.37 (95\% CI: $0.27 ; 0.50)$ and was 0.46 (95\% CI: $0.28 ; 0.78)$ among infants aged $>6$ months [51]. Consistent with these previous studies, we found that breastfeeding was associated with a lower risk of diarrheal and respiratory diseases during the past two weeks in infants under 12 months of age. This could be due to formula-fed infants having fewer opportunities to receive antibodies and bacterial communities from their mothers [9-52].

Many studies have shown that the likelihood of anemia might increase by exclusive breastfeeding for six months and continued breastfeeding after 6 months $[53,54]$. This study found that breastfed infants had lower hemoglobin level than that of formula-fed 
infants, except for the 0-2 months group. However, infants in our study were relatively heavy and had high z-scores of lengths for age and weight for age, especially those breastfeeding infants. This was consistent with two Chinese cohort studies, which showed that breastfeeding beyond six months of age was associated with poor iron status and anemia [55]. In China, the home-made complementary foods for infants were mostly plantbased, the same as that for adults. Parents tended to provide plant-based complementary foods, such as cereal, vegetables, and fruits before animal food, which could help infants to satisfy their iron and zinc requirements [56]. Although the benefits of breastfeeding are indisputable, these findings imply that we should monitor hemoglobin level in infants with prolonged breastfeeding duration. The caregivers should introduce iron-containing complementary foods in time, such as liver paste, yolk, and meat paste, especially in infants who were exclusively breastfed.

This study has several strengths. By use of the most recent nationally representative data available, it provides an up-to-date description of breastfeeding and formula feeding among infants under one year in China. In case of multiple confound variables of infant physical development and diarrheal and respiratory diseases, we adopted a propensity score matching method to control various potential sources of biases, including sociodemographic, biomedical, behavioral, and maternal factors.

The method and data suffer from some limitations. First, although being a powerful and commonly used approach for decreasing bias in observational studies, propensity score matching has statistical limitations. Despite many covariates had been considered in our analysis, some important factors that could affect infants' physical development were left out due to a lack of data, such as seasonal influence, vaccination information, the amount of breastmilk and formula intake, daily dietary energy intake from complementary food, mother's lifestyle during pregnancy, and maternal dietary intake during pregnancy and during lactation. Second, due to the lack of the proportion of breastmilk and formula intake, predominated milk for the infants were unclear. Thus, the effect of mixed feeding was not considered. Third, due to the lack of information, further studies should be conducted to learn about the association between feeding patterns and other diseases, for example allergies, which are also critical health outcomes for infants.

Nonetheless, to the best of our knowledge, this study included the largest and representative infant sample in China, and may thus be useful for illustrating the relation between feeding patterns and health status among 0-11 months infants.

\section{Conclusions}

Breastfeeding and formula feeding has similar effect on infant physical development. Breastfeeding provided protection against diarrheal and respiratory illnesses. Infants aged 3-11 months who were breastfeeding had lower hemoglobin than that of formula-fed infant, indicating that they should consume more iron rich complementary foods. In conclusion, the findings of our study suggest that infants within 12 months should keep breastfeeding, and that policies are needed to achieve longer breastfeeding durations.

Author Contributions: The authors contributions were as follows: Y.F., Y.L. and Y.H. designed the study; Y.F. and Y.L. analysis the data; Y.F. wrote the draft; Y.F., Z.Y., Y.D. and Y.H. performed the surveys; Z.Y. and Y.H. revised the manuscript. All authors have read and agreed to the published version of the manuscript.

Funding: This research was funded by The National Key Research and Development Program of China (No. 2017YFC1601003) and the Major program for Health Care Reform from the Chinese National Health and Family Planning Commission (No. 20120212).

Institutional Review Board Statement: The study was conducted according to the guidelines of the Declaration of Helsinki, and approved by the Ethics Review Board of the Institute for Nutrition and Health, China CDC (protocol code 2013-018 and 15 March 2013).

Informed Consent Statement: Informed consent was obtained from all subjects involved in the study. 
Data Availability Statement: The data cannot be used publicly.

Acknowledgments: We acknowledge all the participants in our study and all the staff working for the China National Nutrition and Health Survey 2013 (CNNHS 2013) from 30 provinces, autonomous regions, and municipalities.

Conflicts of Interest: The authors declare no conflict of interest.

\section{References}

1. Gartner, L.M.; Morton, J.; Lawrence, R.A.; Naylor, A.J.; O'Hare, D.; Schanler, R.J.; Eidelman, A.I. Breastfeeding and the use of human milk. Pediatrics 2005, 115, 496-506.

2. Fewtrell, M.; Wilson, D.C.; Booth, I.; Lucas, A. Six months of exclusive breast feeding: How good is the evidence? BMJ 2010, 342, c5955. [CrossRef]

3. Arifeen, S.; Black, R.E.; Antelman, G.; Baqui, A.; Caulfield, L.; Becker, S. Exclusive breastfeeding reduces acute respiratory infection and diarrhea deaths among infants in Dhaka slums. Pediatrics 2001, 108, E67. [CrossRef]

4. Davisse-Paturet, C.; Adel-Patient, K.; Divaret-Chauveau, A.; Pierson, J.; Lioret, S.; Cheminat, M.; Dufourg, M.; Charles, M.; de Lauzon-Guillain, B. Breastfeeding Status and Duration and Infections, Hospitalizations for Infections, and Antibiotic Use in the First Two Years of Life in the ELFE Cohort. Nutrients 2019, 11, 1607. [CrossRef]

5. Victora, C.G.; Bahl, R.; Barros, A.J.; França, G.V.; Horton, S.; Krasevec, J.; Murch, S.; Sankar, M.J.; Walker, N.; Rollins, N.C. Breastfeeding in the 21st century: Epidemiology, mechanisms, and lifelong effect. Lancet 2016, 387, 475-490. [CrossRef]

6. Quesada, J.A.; Méndez, I.; Martín-Gil, R. The economic benefits of increasing breastfeeding rates in Spain. Int. Breastfeed. J. 2020, 15, 34. [CrossRef]

7. Field, C.J. The immunological components of human milk and their effect on immune development in infants. J. Nutr. 2005, 135, 1-4. [CrossRef] [PubMed]

8. Eiwegger, T.; Stahl, B.; Schmitt, J.; Boehm, G.; Gerstmayr, M.; Pichler, J.; Dehlink, E.; Loibichler, C.; Urbanek, R.; Szépfalusi, Z. Human milk-Derived oligosaccharides and plant-derived oligosaccharides stimulate cytokine production of cord blood T-cells in vitro. Pediatr. Res. 2004, 56, 536-540. [CrossRef]

9. Hunt, K.M.; Foster, J.A.; Forney, L.J.; Schütte, U.; Beck, D.L.; Zaid, A.; Fox, L.K.; Williams, J.E.; Mcguire, M.K.; Mcguire, M.A. Characterization of the Diversity and Temporal Stability of Bacterial Communities in Human Milk. PLoS ONE 2011, 6, e21313. [CrossRef]

10. Assembly, W. Global Strategy for Infants and Young Child Feeding; World Health Organization: Geneva, Switzerland, 2009.

11. Xu, F.; Qiu, L.; Binns, C.W.; Liu, X. Breastfeeding in China: A review. Int. Breastfeed. J. 2009, 4, 6. [CrossRef]

12. Wu, H.H.; Zhang, Y.Q.; Zong, X.N.; Li, H. Changes of feeding patterns in Chinese city children under 2 years from 1985 to 2015 : Results from a series of national cross-sectional surveys. World J. Pediatr. 2019, 15, 176-181. [CrossRef]

13. Duan, Y.; Yang, Z.; Lai, J.; Yu, D.; Chang, S.; Pang, X.; Jiang, S.; Zhang, H.; Bi, Y.; Wang, J.; et al. Exclusive Breastfeeding Rate and Complementary Feeding Indicators in China: A National Representative Survey in 2013. Nutrients 2018, 10, 249. [CrossRef] [PubMed]

14. Druet, C.; Stettler, N.; Sharp, S.; Simmons, R.K.; Ong, K.K. Prediction of childhood obesity by infancy weight gain: An individuallevel meta-analysis. Paediatr. Perinat Epidemiol. 2011, 26, 19-26. [CrossRef] [PubMed]

15. Yan, J.; Liu, L.; Zhu, Y.; Huang, G.; Wang, P.P. The association between breastfeeding and childhood obesity: A meta-analysis. BMC Public Health 2014, 14, 1267. [CrossRef]

16. Bell, K.A.; Wagner, C.L.; Feldman, H.A.; Shypailo, R.J.; Belfort, M.B. Associations of infant feeding with trajectories of body composition and growth. Am. J. Clin. Nutr. 2017, 106, 491-498. [CrossRef]

17. Fall, C.H.; Borja, J.B.; Osmond, C.; Richter, L.; Bhargava, S.K.; Martorell, R.; Stein, A.D.; Barros, F.C.; Victora, C.G. Infant-feeding patterns and cardiovascular risk factors in young adulthood: Data from five cohorts in low- and middle-income countries. Int. J. Epidemiol. 2011, 40, 47-62. [CrossRef]

18. Graulau, R.E.; Banna, J.; Campos, M.; Gibby, C.; Palacios, C. Amount, Preparation and Type of Formula Consumed and Its Association with Weight Gain in Infants Participating in the WIC Program in Hawaii and Puerto Rico. Nutrients 2019, 11, 695. [CrossRef]

19. Patro-Gołab, B.; Zalewski, B.M.; Polaczek, A.; Szajewska, H. Duration of Breastfeeding and Early Growth: A Systematic Review of Current Evidence. Breastfeed. Med. 2019, 14, 218-229. [CrossRef]

20. Bernardo, H.; Cesar, V.; World Health Organization. Long-Term Effects of Breastfeeding a Systematic Review; World Health Organization: Geneva, Switzerland, 2013.

21. Arora, A.; Manohar, N.; Hayen, A.; Bhole, S.; Eastwood, J.; Levy, S.; Scott, J.A. Determinants of breastfeeding initiation among mothers in Sydney, Australia: Findings from a birth cohort study. Int. Breastfeed J. 2017, 12, 39. [CrossRef]

22. Hayashida, K.; Nakatsuka, M. Promoting factors of physical and mental development in early infancy: A comparison of preterm delivery/low birth weight infants and term infants. Environ. Health Prev. Med. 2014, 19, 160-171. [CrossRef]

23. Walker, S.P.; Wachs, T.D.; Gardner, J.M.; Lozoff, B.; Wasserman, G.A.; Pollitt, E.; Carter, J.A. Child development: Risk factors for adverse outcomes in developing countries. Lancet 2007, 369, 145-157. [CrossRef] 
24. Black, R.E. Patterns of Growth in Early Childhood and Infectious Disease and Nutritional Determinants. Nestle Nutr. Inst. Workshop Ser. 2017, 87, 63-72. [PubMed]

25. El, H.C.; Nunes, M.L. Sleep and weight-height development. J. Pediatr. 2019, 95 (Suppl. S1), S2-S9.

26. Chaput, J.P.; Gray, C.E.; Poitras, V.J.; Carson, V.; Gruber, R.; Birken, C.S.; MacLean, J.E.; Aubert, S.; Sampson, M.; Tremblay, M.S. Systematic review of the relationships between sleep duration and health indicators in the early years (0-4 years). BMC Public Health 2017, 17, 855. [CrossRef]

27. Gross, R.S.; Mendelsohn, A.L.; Yin, H.S.; Tomopoulos, S.; Gross, M.B.; Scheinmann, R.; Messito, M.J. Randomized controlled trial of an early child obesity prevention intervention: Impacts on infant tummy time. Obesity 2017, 25, 920-927. [CrossRef]

28. Grote, V.; Theurich, M.; Luque, V.; Gruszfeld, D.; Verduci, E.; Xhonneux, A.; Koletzko, B. Complementary Feeding, Infant Growth, and Obesity Risk: Timing, Composition, and Mode of Feeding. Nestle Nutr. Inst. Workshop Ser. 2018, 89, 93-103. [PubMed]

29. Vehapoglu, A.; Yazıcı, M.; Demir, A.D.; Turkmen, S.; Nursoy, M.; Ozkaya, E. Early infant feeding practice and childhood obesity: The relation of breast-feeding and timing of solid food introduction with childhood obesity. J. Pediatric Endocrinol. Metab. 2014, 27, 1181-1187. [CrossRef]

30. Goldstein, R.F.; Abell, S.K.; Ranasinha, S.; Misso, M.; Boyle, J.A.; Black, M.H.; Li, N.; Hu, G.; Corrado, F.; Rode, L.; et al. Association of Gestational Weight Gain With Maternal and Infant Outcomes: A Systematic Review and Meta-analysis. JAMA 2017, 317, 2207-2225. [CrossRef]

31. Kattula, D.; Sarkar, R.; Sivarathinaswamy, P.; Velusamy, V.; Venugopal, S.; Naumova, E.N.; Muliyil, J.; Ward, H.; Kang, G. The first 1000 days of life: Prenatal and postnatal risk factors for morbidity and growth in a birth cohort in southern India. BMJ Open 2014, 4, e5404. [CrossRef] [PubMed]

32. Lenja, A.; Demissie, T.; Yohannes, B.; Yohannis, M. Determinants of exclusive breastfeeding practice to infants aged less than six months in Offa district, Southern Ethiopia: A cross-sectional study. Int. Breastfeed. J. 2016, 11, 32. [CrossRef] [PubMed]

33. WHO. Child Growth Standards based on lengthheight, weight and age. Acta Paediatr. 2006, 95, 76-85.

34. Guidelines on Physical Activity, Sedentary Behaviour and Sleep for Children under 5 Years of Age; World Health Organization: Geneva, Switzerland, 2019.

35. Rasmussen, K.; Yaktine, A. Committee to Reexamine IOM Pregnancy Weight Guidelines; National Academies Press (US): Washington, DC, USA, 2009.

36. Morgan, C.J. Reducing bias using propensity score matching. J. Nucl. Cardiol. 2018, 25, 404-406. [CrossRef]

37. Rosenbaum, P.R.; Rubin, D.B. The Central Role of the Propensity Score in Observational Studies for Causal Effects. Biometrika 1983, 70, 41-55. [CrossRef]

38. Guendelman, S.; Kosa, J.L.; Pearl, M.; Graham, S.; Goodman, J.; Kharrazi, M. Juggling Work and Breastfeeding: Effects of Maternity Leave and Occupational Characteristics. Pediatrics 2009, 123, 38-46. [CrossRef]

39. Steurer, L.M. Maternity Leave Length and Workplace Policies' Impact on the Sustainment of Breastfeeding: Global Perspectives. Public Health Nurs. 2017, 34, 286-294. [CrossRef]

40. Abou-ElWafa, H.S.; El-Gilany, A.H. Maternal work and exclusive breastfeeding in Mansoura, Egypt. Fam. Pract. 2019, 36, 568-572. [CrossRef] [PubMed]

41. Ickes, S.B.; Oddo, V.M.; Sanders, H.K.; Nduati, R.; Denno, D.M.; Myhre, J.A.; Kinyua, J.; Iannotti, L.L.; Singa, B.; Farquhar, C.; et al. Formal maternal employment is associated with lower odds of exclusive breastfeeding by 14 weeks postpartum: A cross-sectional survey in Naivasha, Kenya. Am. J. Clin. Nutr. 2021, 113, 562-573. [CrossRef]

42. Baker, M.; Milligan, K. Maternal employment, breastfeeding, and health: Evidence from maternity leave mandates. J. Health Econ. 2008, 27, 871-887. [CrossRef] [PubMed]

43. Ogbuanu, C.; Glover, S.; Probst, J.; Liu, J.; Hussey, J. The effect of maternity leave length and time of return to work on breastfeeding. Pediatrics 2011, 127, e1414-e1427. [CrossRef] [PubMed]

44. Gay, M.C.L.; Koleva, P.T.; Slupsky, C.M.; Toit, E.D.; Eggesbo, M.; Johnson, C.C.; Wegienka, G.; Shimojo, N.; Campbell, D.E.; Prescott, S.L.; et al. Worldwide Variation in Human Milk Metabolome: Indicators of Breast Physiology and Maternal Lifestyle? Nutrients 2018, 10, 1151. [CrossRef]

45. Zong, X.; Li, H.; Zhang, Y.; Wu, H. Growth performance comparison of exclusively breastfed infants with partially breastfed and formula fed infants. PLoS ONE 2020, 15, e237067. [CrossRef] [PubMed]

46. Horta, B.L.; Loret, D.M.C.; Victora, C.G. Long-term consequences of breastfeeding on cholesterol, obesity, systolic blood pressure and type 2 diabetes: A systematic review and meta-analysis. Acta Paediatr. 2015, 104, 30-37. [CrossRef]

47. Yadanar; Mya, K.S.; Witvorapong, N. Determinants of breastfeeding practices in Myanmar: Results from the latest nationally representative survey. PLoS ONE 2020, 15, e239515. [CrossRef]

48. Gianni, M.L.; Roggero, P.; Mosca, F. Human milk protein vs. formula protein and their use in preterm infants. Curr. Opin. Clin. Nutr. Metab. Care 2019, 22, 76-81. [CrossRef] [PubMed]

49. Quigley, M.A.; Kelly, Y.J.; Sacker, A. Breastfeeding and hospitalization for diarrheal and respiratory infection in the United Kingdom Millennium Cohort Study. Pediatrics 2007, 119, e837-e842. [CrossRef]

50. Diallo, A.F.; McGlothen-Bell, K.; Lucas, R.; Walsh, S.; Allen, C.; Henderson, W.A.; Cong, X.; McGrath, J. Feeding modes, duration, and diarrhea in infancy: Continued evidence of the protective effects of breastfeeding. Public Health Nurs. 2020, 37, 155-160. [CrossRef] [PubMed] 
51. Horta, B.L.; Victora, C.G.; World Health Organization. Short-Term Effects of Breastfeeding: A Systematic Review on the Benefits of Breastfeeding on Diarrhoea and Pneumonia Mortality; World Health Organization: Geneva, Switzerland, 2013.

52. Hosea, B.H.; Cicalo, M.C.; Holland, C.D.; Field, C.J. The immunological components of human milk. Adv. Food Nutr. Res. 2008, 54, 45-80.

53. Dalili, H.; Baghersalimi, A.; Dalili, S.; Pakdaman, F.; Hassanzadeh, R.A.; Abbasi, K.M.; Rezvany, S.M.; Koohmanaei, S. Is there any relation between Duration of breastfeeding and anemia? Iran J. Ped. Hematol. Oncol. 2015, 5, 218-226.

54. Wang, F.; Liu, H.; Wan, Y.; Li, J.; Chen, Y.; Zheng, J.; Huang, T.; Li, D. Prolonged Exclusive Breastfeeding Duration Is Positively Associated with Risk of Anemia in Infants Aged 12 Months. J. Nutr. 2016, 146, 1707-1713. [CrossRef]

55. Clark, K.M.; Li, M.; Zhu, B.; Liang, F.; Shao, J.; Zhang, Y.; Ji, C.; Zhao, Z.; Kaciroti, N.; Lozoff, B. Breastfeeding, Mixed, or Formula Feeding at 9 Months of Age and the Prevalence of Iron Deficiency and Iron Deficiency Anemia in Two Cohorts of Infants in China. J. Pediatr. 2017, 181, 56-61. [CrossRef] [PubMed]

56. Jing, S.; Dai, Y.; Zhang, S.; Jian, H.; Yang, Z.; Huo, J.; Chen, C. Implementation of a programme to market a complementary food supplement (Ying Yang Bao) and impacts on anaemia and feeding practices in Shanxi, China. Matern. Child Nutr. 2011, 7, 96-111. 